\title{
MONITORAMENTO DE SEDIMENTOS E REJEITOS DA USINA DE FERRO CARAJÁS ATRAVÉS DO SISTEMA DE GEOBARRAGEM (ESTUDO DE CASO)
}

\author{
José Carlos Oliveira ${ }^{1}$, Fábio Valério Câmara Xavier ${ }^{2}$, Teruo Sato ${ }^{3}$, José \\ AnselmoCampos ${ }^{4}$, Mauro Sérgio Miranda Walter ${ }^{5}$ \\ ${ }^{1}$ Técnico Especializado de Produção - Gerência de Planejamento e Processos - Cia. Vale \\ do Rio Doce. \\ carlos.oliveira@cvrd.com.br \\ ${ }^{2}$ Geólogo - Geoexplore Consultoria e Serviços \\ ${ }^{3}$ Engenheiro de Minas - Companhia Vale do Rio Doce \\ ${ }^{4}$ Engenheiro de Minas - Companhia Vale do Rio Doce \\ ${ }^{5}$ Gerência de Planejamento e Processos - Companhia Vale do Rio Doce
}

Trabalho apresentado no XXI ENTMME, Natal-RN, novembro, 2005

\section{RESUMO}

Com o objetivo de dar suporte atividades diárias de controle e para auxiliar a tomada de decisões na operação das barragens das minas de ferro da CVRD, Carajás-PA, foi desenvolvido, em parceria com a empresa Geoexplore Consultoria e Serviços, um sistema de Gestão de Barragens baseado em geotecnologias. O GeoBarragem foi concebido para atuar na coleta de dados de campo, no armazenamento dos dados relacionados à gestão das barragens, na análise e integração espacial e na simulação do preenchimento das barragens. É composto por um coletor de dados através de Handheld, um Sistema Gerenciador de Banco de Dados, um software para integração e análise espacial de dados e um simulador de preenchimento de barragens.

Palavras chave: Monitoramento; Sedimentos e rejeitos; Geobarragem Minas de Ferro de Carajás. 


\section{MONITORAMENTO DE SEDIMENTOS E REJEITOS DA USINA DE FERRO CARAJÁS ATRAVÉS DO SISTEMA DE GEOBARRAGEM (ESTUDO DE CASO)}

\section{INTRODUÇÃO}

As minas de ferro da Companhia Vale do Rio Doce (CVRD) localizadas em Carajás, estado do Pará (figura 01), possuem uma produção média de 70 milhões de toneladas de minério de ferro por ano. Ver Figura 1. Para o processamento físico deste minério, geramse cerca de 8,5 milhões de toneladas de rejeito de minério de ferro por ano que é destinado às duas barragens de rejeito, denominadas de Gelado e Geladinho.

Dentro da política ambiental e de qualidade da CVRD, o destino do rejeito do processo de beneficiamento do minério de ferro e o reaproveitamento da água utilizada neste processo são tratados de forma séria e prioritária.

Com o intuito de monitorar o aporte de resíduos da usina (granulometria média $<0,038 \mathrm{~mm}$ ), otimizar o monitoramento geotécnico e ambiental das barragens de rejeito e de otimizar o preenchimento destas barragens, foi desenvolvido para a CVRD, através da parceria com a empresa Geoexplore Consultoria e Serviços, um Sistema de Gestão de Barragens (GeoBarragem) usando recursos de geoprocessamento.

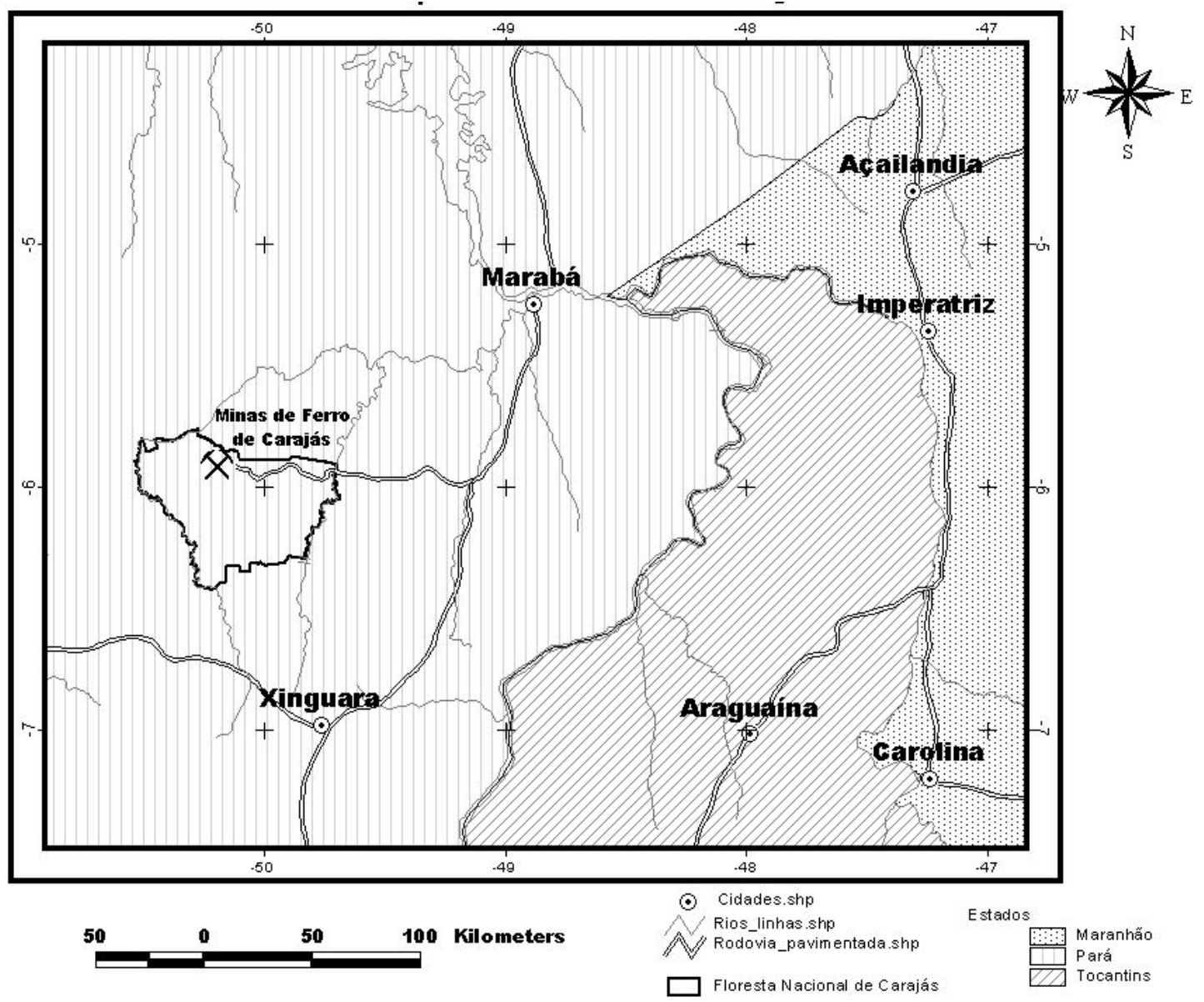

FIGURA 1:Mapa de Localização. 


\section{PROJETO FERRO CARAJÁS E BARRAGENS DE REJEITO}

Desde o início da implantação do Projeto ferro Carajás, a CVRD dedicou cuidado especial e constante à conservação e recuperação do ecossistema da região, um dos mais ameaçados do planeta.

Cerca de US\$ 67 milhões foram aplicados em programas de pesquisa, recuperação e conservação do meio ambiente e em ações de apoio ao desenvolvimento socioeconômico.

Menos de 2\% dos 412 mil hectares que compõem a Floresta Nacional de Carajás são ocupados com atividades de mineração e infra-estrutura. Na área restante, a floresta amazônica permanece intocada e protegida.

Para aferir a eficácia do seu Programa de Controle Ambiental, a Companhia desenvolve criterioso programa de monitoramento de água e ar.

O Sistema de Gestão Ambiental das minas de ferro e manganês de Carajás recebeu a Certificação ISO 14001, após ter sido auditado pela Det Norske Veritas-DNV.

Dentro do contexto de preservação ambiental, a fim de conter o rejeito do processamento do minério de ferro, composto essencialmente por finos de minério de ferro, a CVRD dispõe de duas barragens de rejeito, sendo estas a barragem do Gelado, de maior porte e destinada a praticamente todo o rejeito oriundo do processo; e a barragem do Geladinho, de menor porte e atualmente destinada à contenção dos finos carreados pelos sistemas de drenagem pluvial.

A crescente produção de minério de ferro apresentada pelas minas de Carajás fomenta a necessidade de efetuar-se um controle rigoroso do preenchimento das barragens de rejeito, ver Figura 2.

O preenchimento desordenado destas possui como resultados a antecipação de obras onerosas de alteamentos, por exemplo, de forma que se fazem necessárias medidas complementares ao simples monitoramento. Estudos da evolução do preenchimento das barragens ao longo dos anos são uma forma de acompanhamento e controle.

Além de acompanhamento piezométrico, inspeções ambientais, geotécnicas e hidráulicas e de constantes manutenções, são ainda realizados levantamentos batimétricos trimestralmente.

\section{O SISTEMA GEOBARRAGEM}

O GeoBarragem é um produto que integra ramos distintos do geoprocessamento aumentando o poder de análise dos dados relacionados a barragens de rejeitos, suportando as necessidades de gerenciamento, manutenção e tomada de decisões. Ele é composto por um coletor de dados, um sistema gerenciador de banco de dados (SGBD), um software para integração e análise espacial de dados e um simulador de preenchimento de barragens.

O módulo de coleta de dados é constituído pelo software Logmate, de propriedade da Surpac Minex Group (SMG), que trabalha em Handheld. Através dele, o técnico de campo armazena as informações observadas no local diretamente no banco de dados, ver Figura 3. 
Este procedimento possibilita a padronização da coleta dos dados e diminuindo a possibilidade de erros gerados devido à manipulação desnecessária dos dados.

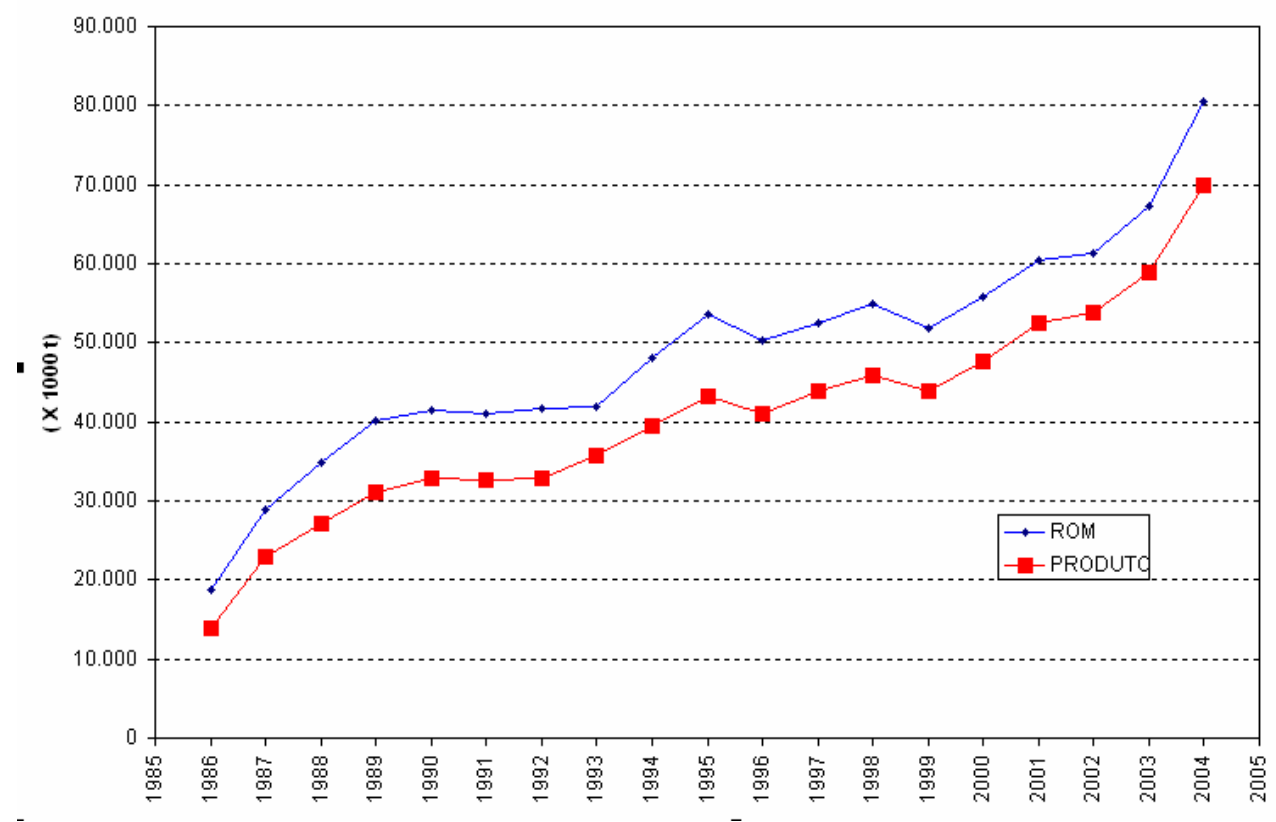

FIGURA 2: Balanço das produções da usina de beneficiamento de minério de ferro - Carajás.

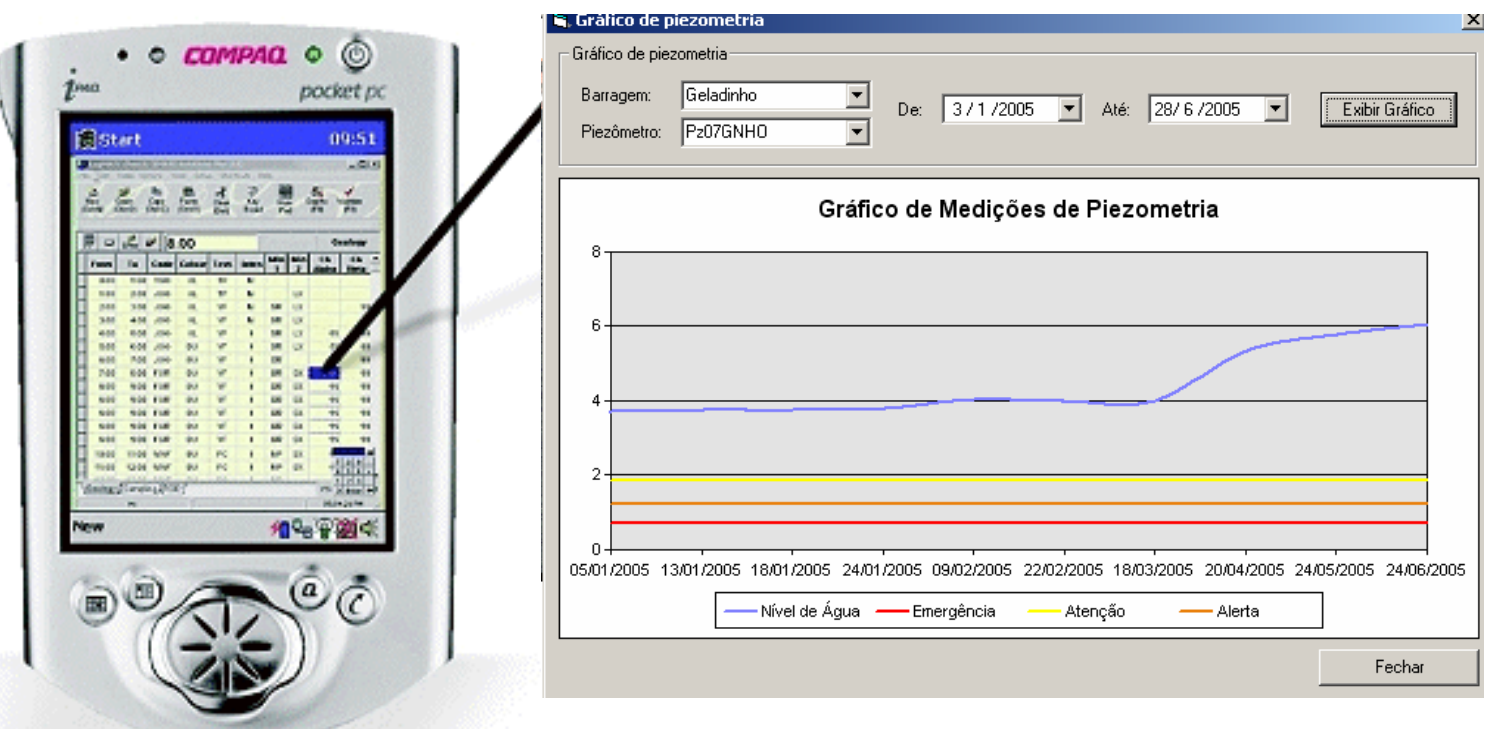

FIGURA 3: Software LogMate da Surpac Minex Group (SMG) em handheld. Os dados são armazenados no local de coleta diretamente no banco de dados.

O módulo de SGBD tem a função de armazenamento e geração de relatórios dos dados que estão, direta ou indiretamente, relacionados às barragens. Devido à concepção de manter um banco de dados único, servindo de base para os outros módulos do sistema, viabiliza-se dados consistentes, atualizados, sempre disponíveis e seguros.

As informações estão divididas nas áreas de inspeção e gestão de barragens. 
Na área de inspeção de barragens o técnico responsável tem a opção de cadastro de todos os itens observados durante a inspeção contemplando manutenção das calhas de rejeito, canaletas, piezômetros, talude, estrutura da barragem, entre outros. O GeoBarragem foi desenvolvido para que, após os cadastro dos dados, os itens fossem classificados segundo sua urgência para consulta e impressão de relatórios, além de manter o histórico das inspeções, ver Figura 4.

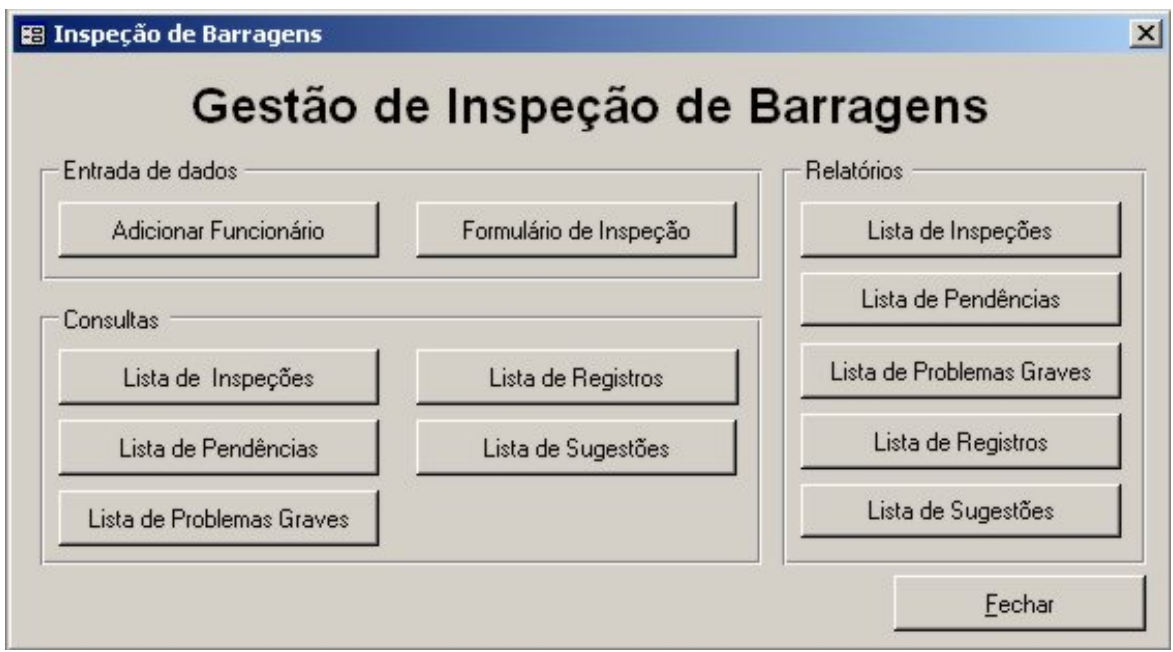

FIGURA 4:Interface gráfica do formulário de inspeção de barragens.

A área de gestão de barragens contempla as necessidades de armazenamento de dados referentes à meteorologia, batimetria, piezometria, estabilidade do talude, quantidade de água e rejeito despejado, nível da barragem, sondagem, cadastro de equipamentos, dados de produção da usina, custos, entre outros, ver Figura 5. Esta interface possibilita também a importação direta dos dados do coletor de campo (LogMate) e a geração de relatórios automatizados constituídos por listas de estações, medições e equipamentos, além de itens gerados a partir de cálculos específicos respondendo às necessidades básicas para a operação do sistema usina-barragem.

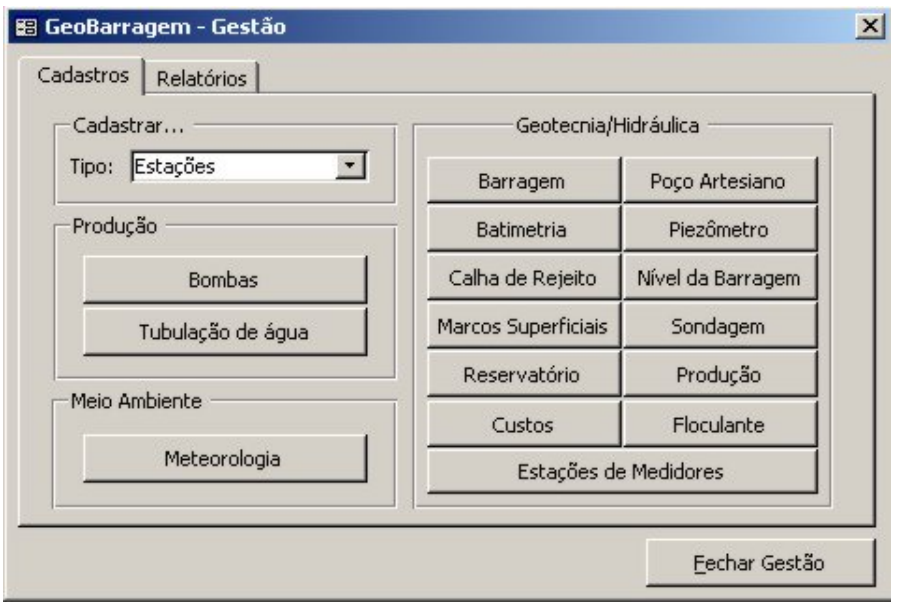

FIGURA 5:Interface gráfica do formulário de gestão de barragens. 
Para uma maior capacidade de análise dos dados, o GeoBarragem possibilita a integração do banco de dados com os softwares ArcGIS da ESRI e Tailings da Surpac Minex Group (SMG).

No ArcGIS, os dados são manuseados em um Sistema de Informações Geográficas onde os dados espaciais podem ser integrados a outras informações como hidrografia, hipsometria, vias de acessos, infra-estrutura e imagens de satélite, ver Figura 6. Desta forma, através das ferramentas que o software dispõe, as tarefas de atualização dos dados, consultas, análise espacial, confecção de gráficos, relatórios e mapas, são bastante simplificadas.

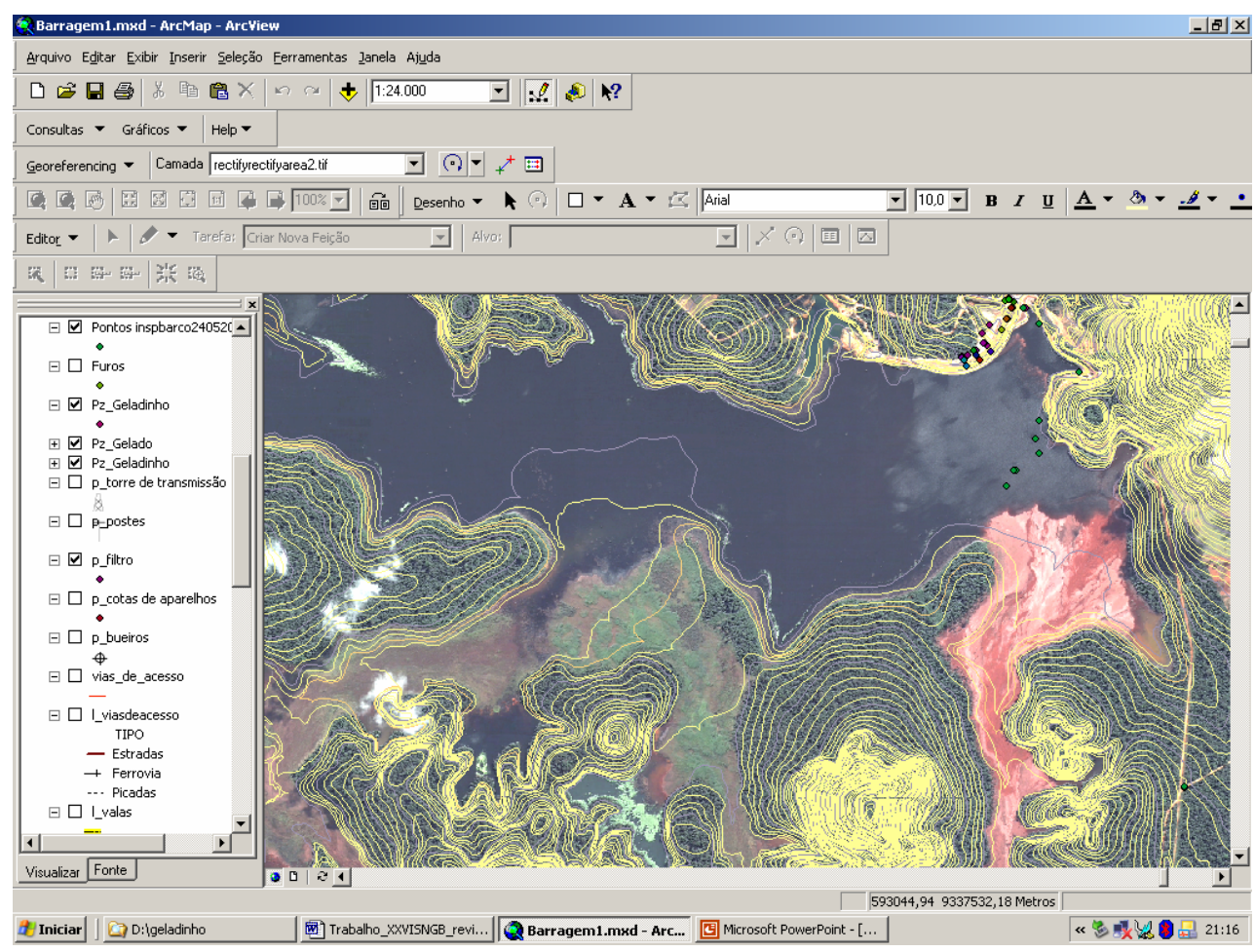

FIGURA 6:Interface gráfica do ArcGIS onde pode ser vista a barragem do Gelado e a barra de ferramentas do sistema GeoBarragem.

Com o intuito de facilitar as análises dos dados, foi criada uma barra de ferramentas para a interface do ArcGIS com as funções de consultas e geração de gráficos. Com ela, é possível espacializar pontos resultantes de consultas podendo ser convertidos em arquivos do formato shapefiles, mapas de isolinhas, etc. Ver Figura 6.

O software Tailings constitui o módulo de simulação de preenchimento de barragens onde, através de parâmetros técnicos do material depositado, dados de produção, localização dos pontos de descarga e batimetria da barragem, pode-se visualizar a situação da barragem ao longo do tempo. Esta visualização é feita através de modelos digitais de terreno, seções verticais e horizontais, mapas de isovalores e relatórios, ver Figura 7.

Este módulo permite otimizar a deposição de rejeitos e aumentar a vida média das barragens evitando obras de engenharia muitas vezes precipitadas e onerosas, além de evitar intervenções desnecessárias no meio ambiente. Esta ferramenta permite ainda fazer uma avaliação do rejeito dando suporte a estudos e modelagens avançados do 
aproveitamento econômico através da possível retomada do minério fino depositado nas barragens [1].

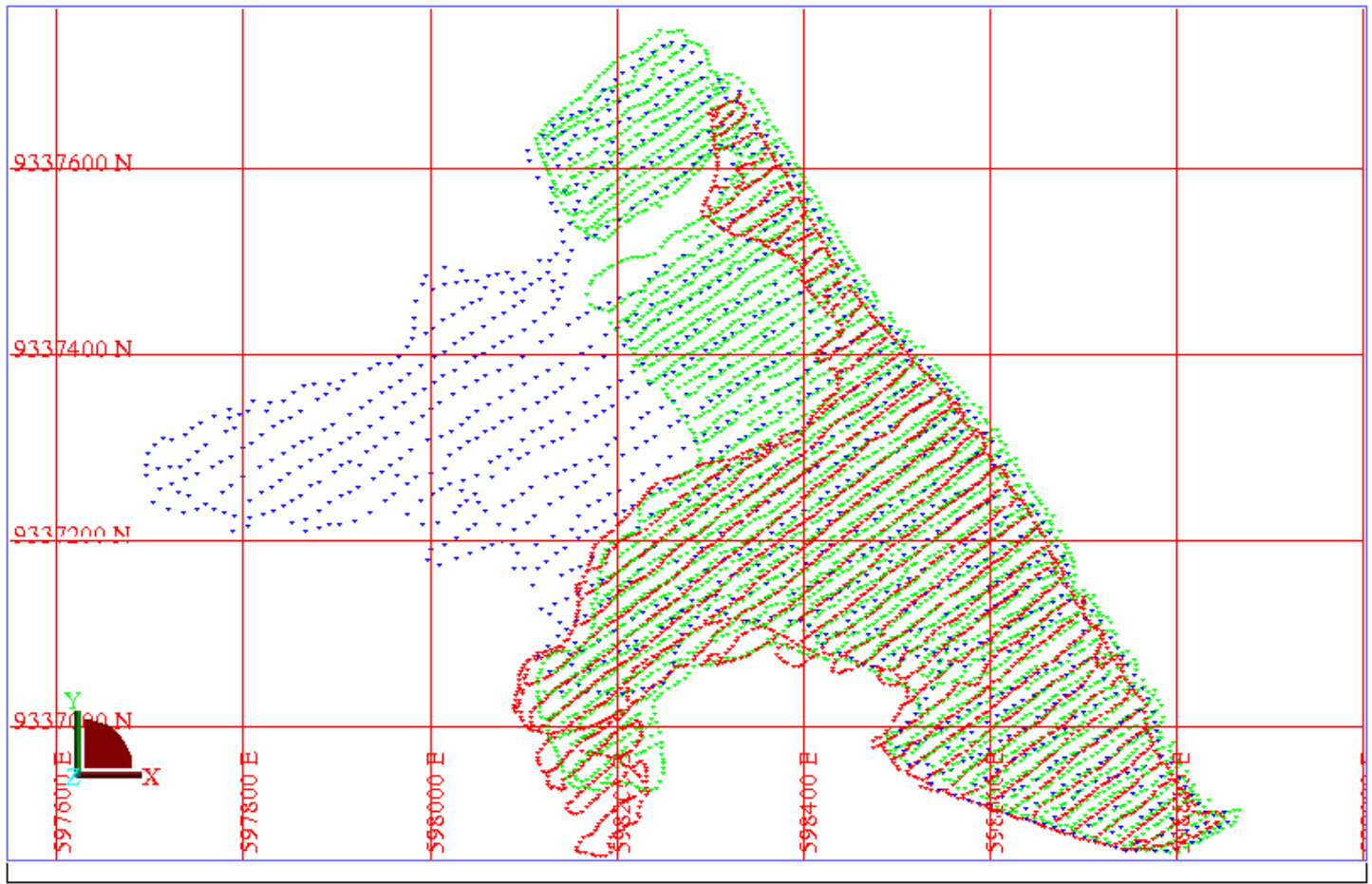

FIGURA 7:Interface gráfica do módulo Tailings da Surpac onde pode ser vista a área da barragem do Geladinho com cores associadas a batimetria da barragem.

\section{CONCLUSÕES}

Barragens de rejeitos como as das minas de ferro de Carajás são sem dúvida obras de grande importância econômica e ambiental devendo ser tratadas de forma responsável. A complexidade operacional de obras como esta gera um grande volume de dados e informações que devem ser manuseados de forma organizada e eficiente. Neste sentido, as técnicas e os recursos do geoprocessamento desempenham um papel indispensável auxiliando em todas as etapas da operação de barragens.

O GeoBarragem foi desenvolvido para atuar na coleta de dados de campo, no armazenamento seguro e íntegro dos dados, na análise e integração espacial e na simulação do preenchimento das barragens.

O desenvolvimento do GeoBarragem representa um importante passo dado pelos responsáveis pela operação das barragens de rejeito das minas de ferro de Carajás, uma vez que este sistema desempenhará um papel fundamental no processo, o suporte na tomada de decisões.

\section{REFERÊNCIAS BIBLIOGRÁFICAS}

[1] SURPAC MINEX GROUP - "Model Tailings".

In: http://www.surpac.com/refman/default/mining/tailings.htm Acesso em: 10/01/2005. 